\title{
Psychometric properties of the Fagerström Test for Nicotine Dependence ${ }^{*, * *}$
}

\author{
As propriedades psicométricas do Teste de \\ Fagerström para Dependência de Nicotina
}

\author{
lzilda Carolina de Meneses-Gaya, Antonio Waldo Zuardi, \\ Sonia Regina Loureiro, José Alexandre de Souza Crippa
}

\begin{abstract}
Objective: The Fagerström Test for Nicotine Dependence (FTND) is a screening instrument for physical nicotine dependence and is extensively used in various countries. The objective of the present report was to review articles related to the psychometric properties of the FTND. Methods: A systematic search for articles published up through December of 2007 was carried out in various electronic databases. The following search terms were used: "Fagerström Test for Nicotine Dependence"; "FTND"; "psychometric"; "validity"; "reliability"; "feasibility"; and "factors". We included articles published in English, Spanish or Portuguese and in which the psychometric properties of the FTND were evaluated. Results: Twenty-six studies related to the psychometric properties of the FTND were identified in the indexed literature. Analysis of the studies confirmed the reliability of the FTND for the assessment of nicotine dependence in different settings and populations. Conclusions: Further validation studies using previously validated instruments as a comparative measure are needed before the extensive use of the FTND can be justified on the basis of its psychometric qualities.
\end{abstract}

Keywords: Tobacco use disorder; Psychometrics; Tobacco; Reproducibility of results.

\section{Resumo}

Objetivo: 0 Fagerström Test for Nicotine Dependence (FTND, Teste de Fagerström para Dependência de Nicotina) é um instrumento de rastreamento para dependência física de tabaco, amplamente utilizado em diversos países. Objetivou-se realizar uma revisão de artigos relacionados às propriedades psicométricas do FTND. Métodos: Uma busca sistemática foi realizada usando-se vários indexadores eletrônicos até dezembro de 2007, com os seguintes descritores: "Fagerström Test for Nicotine Dependence"; "FTND"; "psychometric"; "validity"; "reliability"; "feasibility"; e "factors". Foram incluídos os artigos relacionados à avaliação das propriedades psicométricas do FTND publicados em inglês, espanhol e português. Resultados: Vinte e seis estudos relativos às propriedades psicométricas do FTND foram identificados na literatura indexada. A análise dos estudos confirmou a confiabilidade do FTND na avaliação da dependência de tabaco em diferentes contextos e populações. Conclusões: Futuros estudos de validação, utilizando como medida comparativa instrumentos aferidos, de modo a referendar o seu extenso uso pelas suas qualidades psicométricas ainda são necessários.

Descritores: Transtorno por uso de tabaco; Psicometria; Tabaco; Reprodutibilidade dos testes.

\section{Introduction}

Nicotine dependence syndrome is recognized as one of the major public health problems in the world. It is estimated that, during the 20th century, approximately 100 million people died of diseases related to the smoking habit. Various studies have indicated that smoking reduces life expectancy, increases overall medical costs and contributes to a loss of productivity. ${ }^{(1)}$

\footnotetext{
* Study carried out in the Department of Neurosciences and Behavior. University of São Paulo at Ribeirão Preto School of Medicine, Ribeirão Preto, Brazil AND INCT Translational Medicine, Brazil.

Correspondence to: Correspondence to: José Alexandre S. Crippa. Departamento de Neurociências e Ciências do Comportamento, Faculdade de Medicina de Ribeirão Preto, Universidade de São Paulo Hospital das Clínicas, $3^{\circ}$ andar, Av. Bandeirantes, 3900, CEP 14049-900, Ribeirão Preto, São Paulo, SP, Brasil.

Tel 5516602 2201. E-mail: jcrippa@fmrp.usp.br

Financial support: 1.C.M.G. is the recipient of a fellowship from the Fundação de Amparo à Pesquisa do Estado de São Paulo (FAPESP, Foundation for the Support of Research in the State of São Paulo). A.W.Z, S.R.L. and J.A.S.C. are the recipients of fellowships from the Conselho Nacional de Desenvolvimento Científico e Tecnológico (CNPq, National Council for Scientific and Technological Development). This study also received financial support from the Fundação de Apoio ao Ensino, Pesquisa e Assistência (FAEPA, Foundation for the Support of Instruction, Research and Treatment) of the University of São Paulo at Ribeirão Preto School of Medicine Hospital das Clínicas. Submitted: 7 May 2008. Accepted, after review: 12 June 2008

**A versão completa em português deste artigo está disponível em www.jornaldepneumologia.com.br
} 
Although the consequences are well known, the absolute number of smokers continues to increase worldwide, particularly in developing countries, indicating that having information regarding those consequences does not induce people to permanently abandon the smoking habit, nor does it prevent new smokers from taking up the habit. ${ }^{(2)}$

Studies evaluating the smoking habit, together with the variables that affect the onset, maintenance and cessation of smoking have shown that, due to a combination of psychological, physiological and social variables, the problems related to tobacco consumption and nicotine dependence are extremely complex. ${ }^{(3)}$

The assessment of nicotine dependence is indispensable in epidemiological studies and in investigations of the effects of nicotine, as well as in studies regarding the treatment of smoking and of the various smoking-related diseases. In recent years, instruments for the screening of nicotine dependence have become important research tools. ldeally, these instruments should provide accurate, reproducible and relevant measurements. Their use provides better recording of information, especially at facilities that have a high turnover of professional staff. Such instruments also permit the comparison of similar assessment results and minimize the effect of subjective factors in the process of data collection and recording.

Several instruments have been developed to assess physical dependence on nicotine. The most widely used of such instruments are the Fagerström Tolerance Questionnaire (FTQ), created in 1978, ${ }^{(4)}$ and its improved version, the Fagerström Test for Nicotine Dependence (FTND, Appendix 1), both devised by Fagerström et al. ${ }^{(5,6)}$ The FTND was developed mainly because the FTQ had significant psychometric disadvantages, such as unacceptable internal consistency, poor criterion validity and a multifactorial structure. ${ }^{(7)}$

The FTND was initially developed to determine whether or not nicotine replacement therapy is needed to treat withdrawal syndrome. The instrument consists of six of the original FTQ items with revised scoring for two questions. It is easily understood and rapidly applied. The scores obtained on the test permit the classification of nicotine dependence into five levels: very low (0 to 2 points); low (3 to 4 points); moderate ( 5 points); high (6 to 7 points); and very high (8 to 10 points).

The FTND has been translated into numerous languages and is used in countries such as France, ${ }^{(8,9)}$ Spain, ${ }^{(10,11)}$ Brazil, $^{(3)}$ China, ${ }^{(12)}$ Japan, ${ }^{(13)}$
Holland, ${ }^{(14,15)}$ Germany ${ }^{(16)}$ and Turkey. ${ }^{(17)}$ The reported results obtained with these translated versions were similar to those obtained with the original version.

A modified version of the FTND for assessment of smokeless tobacco users has also been developed. ${ }^{(18)}$ In addition, a reduced version of the FTQ has also been proposed: the Heaviness of Smoking Index (HSI), which consists of two questions (FTQ questions one and four) related to the need for nicotine replacement and to the level of tobacco consumption. ${ }^{(19)}$ Studies evaluating the $\mathrm{HSI}$ and comparing it to the FTND have shown that the HSI results are similar to those obtained with the FTND. . $^{(8,9,11,20-22)}$

The objective of the present study was to perform a critical review of articles in the indexed literature related to the psychometric properties of the FTND.

\section{Methods}

A systematic search of the literature published up through December of 2007 was carried out using the following electronic databases: Medline; LILACS; SciELO; Web of Science; and Psyclnfo. The search terms were "Fagerström Test for Nicotine Dependence", "FTND", "psychometric", "validity", "reliability", "feasibility" and "factors". The original articles obtained via this search were then reviewed for additional references. The computer-based search of the literature was augmented with extensive hand searches of the bibliographies.

We included articles published in English, Spanish or Portuguese and in which the psychometric properties of the FTND were evaluated. Studies dealing with the clinical and epidemiological aspects of smoking-related problems were excluded, as were those evaluating reduced or modified versions of the FTND and those dealing with the efficacy of treatments for dependence.

Twenty-six studies were identified and analyzed. Sociodemographic data related to the samples included in the studies analyzed are shown in Table 1.

\section{Results}

\section{Test-retest reliability}

The test-retest reliability of the FTND was assessed in eight studies (Table 2). The time elapsed between evaluations varied among those 
Table 1 - Sociodemographic characteristics of studies evaluating the psychometric qualities of the Fagerström Test for Nicotine Dependence.

\begin{tabular}{|c|c|c|c|c|c|}
\hline Authors & Country & Subjects & Number & $\begin{array}{l}\text { Gender, } \\
\mathrm{M} / \mathrm{F}(\%)\end{array}$ & $\begin{array}{c}\text { Mean } \\
\text { age }\end{array}$ \\
\hline Heatherton et al. ${ }^{(6)}$ & USA & Adult smokers & 254 & $44 / 56$ & 33.5 \\
\hline \multirow[t]{2}{*}{ Kozlowski et al. ${ }^{(20)}$} & USA & Smokers under treatment for smoking & 932 & $35 / 65$ & 40 \\
\hline & & Smokers in a smoking cessation program & 1877 & $36 / 64$ & 44 \\
\hline Payne et al. ${ }^{(23)}$ & USA & $\begin{array}{l}\text { War veteran smokers seeking treatment for } \\
\text { smoking }\end{array}$ & 110 & $71 / 29$ & 49 \\
\hline \multirow[t]{3}{*}{ Pomerleau et al. ${ }^{(24)}$} & USA & Smokers in Michigan & 237 & $56 / 44$ & 29 \\
\hline & & Smokers hospitalized for depression in Paris & 36 & $33 / 67$ & 36 \\
\hline & & Smokers in Michigan & 60 & $75 / 25$ & 29 \\
\hline Mikami et al. ${ }^{(13)}$ & Japan & $\begin{array}{l}\text { Patients hospitalized for cancer of the lung (105) } \\
\text { or for head/neck cancer (46) }\end{array}$ & 151 & $91 / 9$ & 62 \\
\hline Etter et al. ${ }^{(8)}$ & $\begin{array}{c}\text { France/ } \\
\text { Switzerland }\end{array}$ & Light smokers (university students and employees) & 1125 & $40 / 60$ & 28 \\
\hline \multirow[t]{2}{*}{ Haddock et al..$^{(7)}$} & USA & Young smokers in USAF BMT & 7998 & $76 / 24$ & 19 \\
\hline & & Subsample for the reliability study & 1714 & & \\
\hline Carmo et al..$^{(3)}$ & Brazil & Adult smokers & 441 & $43 / 57$ & $18-80$ \\
\hline $\begin{array}{l}\text { Burling \& } \\
\text { Burling }^{(21)}\end{array}$ & USA & $\begin{array}{l}\text { Alcohol-dependent smokers in a rehabilitation } \\
\text { program for veterans }\end{array}$ & 191 & $100 / 0$ & 40 \\
\hline \multirow[t]{2}{*}{ De Leon et al. ${ }^{(11)}$} & USA/Spain & $\begin{array}{l}\text { Smokers with mental disorders (retrospective } \\
\text { analysis) }\end{array}$ & 319 & - & - \\
\hline & & $\begin{array}{l}\text { Smokers without mental disorders (retrospective } \\
\text { analysis) }\end{array}$ & 1323 & & \\
\hline Radzius et al. ${ }^{(25)}$ & USA & Drug users & 541 & $75 / 25$ & 35 \\
\hline Breteler et al. ${ }^{(14)}$ & Holland & Smokers & 1525 & $40 / 60$ & 40 \\
\hline \multirow[t]{2}{*}{ Hughes et al. ${ }^{(26)}$} & USA & Smokers (Sample 1) & 43 & $44 / 56$ & 39 \\
\hline & & Smokers (Sample 2) & 50 & $46 / 54$ & 45 \\
\hline \multirow[t]{2}{*}{ John et al. ${ }^{(16)}$} & Germany & Current smokers (Sample 1) & 1462 & _ & $\mathrm{ND}^{\mathrm{a}}$ \\
\hline & & Current smokers (Sample 2) & 1042 & & \\
\hline \multirow[t]{2}{*}{ Buckley et al. ${ }^{(27)}$} & USA & $\begin{array}{l}\text { Smokers with post-traumatic stress disorder } \\
\text { (Sample 2) }\end{array}$ & 75 & $65 / 35$ & 48 \\
\hline & & $\begin{array}{l}\text { Smokers with post-traumatic stress disorder } \\
\text { (Sample 2) }\end{array}$ & 513 & $98 / 2$ & 50 \\
\hline Chabrol et al..$^{(9)}$ & France & $\begin{array}{l}\text { Smokers working at an Occupational Medicine } \\
\text { Center }\end{array}$ & 749 & $47 / 53$ & - \\
\hline Etter ${ }^{(22)}$ & Switzerland & Smokers with access to the Internet & 802 & $42 / 58$ & 34 \\
\hline Hudmon et al..$^{(28)}$ & USA & $\begin{array}{l}\text { Former smokers evaluated prior to smoking } \\
\text { cessation }\end{array}$ & 28 & - & - \\
\hline Richardson et al. ${ }^{(29)}$ & Canada & Patients admitted for preoperative evaluation & 231 & $48 / 52$ & 50 \\
\hline Steinberg et al. ${ }^{(30)}$ & USA & Smokers with schizophrenia & 108 & $38 / 62$ & 44 \\
\hline \multirow[t]{2}{*}{ Vink et al..$^{(15)}$} & Holland & Smokers & 1378 & $42 / 58$ & 30 \\
\hline & & Former smokers & 1058 & $35 / 65$ & 37 \\
\hline Huang et al. ${ }^{(12)}$ & China & Smokers & 245 & $97 / 3$ & 47 \\
\hline Wellman et al..$^{(31)}$ & USA & Smokers & 1130 & $46 / 54$ & 41 \\
\hline Okuyemi et al. ${ }^{(32)}$ & USA & $\begin{array}{l}\text { Light smokers (Afro-Americans) in a nicotine } \\
\text { replacement study }\end{array}$ & 700 & $33 / 67$ & 45 \\
\hline Sledjeski et al. ${ }^{(33)}$ & USA & Light smokers (college freshmen) & 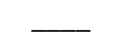 & $52 / 48$ & \\
\hline \multirow[t]{2}{*}{ Weinberger et al. ${ }^{(34)}$} & USA & Smokers with schizophrenia (retrospective analysis) & 181 & $52 / 48$ & 40 \\
\hline & & $\begin{array}{l}\text { Smokers without schizophrenia (retrospective } \\
\text { analysis) }\end{array}$ & 151 & $60 / 40$ & \\
\hline
\end{tabular}

USAF BMT: United States Air Force basic military training; and ND: no data. ${ }^{a}$ Mean age not reported; age range, 20-64 years. 
studies, a fact that might hinder comparisons of the results.

Among the studies of FTND reliability, an outstanding example is that carried out by Mikami et al., ${ }^{(13)}$ which was conducted in Japan and involved a predominantly male sample of patients with cancer of the lung, brain or throat. In that study, the correlation coefficient was 0.75 , although the time between applications was not reported by the authors. In another study, the reliability of the FTND was compared with that of the HSI in light smokers who had been evaluated in a previous seven-month cohort study. ${ }^{(8)}$ Despite the long interval between evaluations, both tests showed high reliability, a slightly higher coefficient $(0.87)$ being obtained with the HSI. Therefore, these instruments can be used in order to evaluate not only heavy smokers but also light smokers.

A six-week "reliability of recall" study was conducted involving a randomly selected subsample of young smokers entering the US Air Force Basic Military Training. ${ }^{(7)}$ Due to the ban on tobacco use during military training, the participants remained abstinent during the sixweek period. All of the participants were asked to complete the FTND questionnaire retrospectively, based on their smoking patterns prior to the period of abstinence. The analysis indicated that the reliability index for the overall score on the FTND was excellent (0.87), factor 1 presenting better reliability (0.87) than did factor 2 (0.67).

In a retrospective study, the FTND was analyzed in a small sample of former smokers participating in an investigation of smoking cessation. ${ }^{(28)}$ By means of a telephone interview, the participants again responded to the test questions referring to past consumption. The results indicated that the FTND had an acceptable reliability index (0.72) when used to assess previous dependence.

Three studies carried out in the United States examined the reliability of the FTND in smokers with psychiatric disorders. The first study involved a sample of subjects with post-traumatic stress disorder and employed a one-week interval

Table 2 - Test-retest reliability in studies evaluating the psychometric qualities of the Fagerström Test for Nicotine Dependence.

\begin{tabular}{|c|c|c|c|c|}
\hline Study & Test & lnterval & Subjects & Reliability \\
\hline \multirow[t]{3}{*}{ Etter et al. ${ }^{(8)}$} & FTND & 7 months & Light smokers & 0.85 \\
\hline & $\mathrm{HSl}$ & & & 0.87 \\
\hline & CPD & & & 0.87 \\
\hline Mikami et al. ${ }^{(13)}$ & FTND & 8-145 days & Cancer patients & 0.75 \\
\hline Haddock et al..$^{(7)}$ & FTND & 6 weeks & Young smokers in USAF BMT & 0.87 \\
\hline Carmo et al. ${ }^{(3)}$ & FTND & 6 weeks & Smokers & 0.91 \\
\hline Buckley et al. ${ }^{(27)}$ & FTND & 1 week & Smokers with post-traumatic stress disorder & 0.82 \\
\hline \multirow[t]{2}{*}{ Hudmon et al. ${ }^{(28)}$} & FTND & $5-12$ years & Former smokers & 0.72 \\
\hline & FTQ & & & 0.62 \\
\hline \multirow[t]{4}{*}{ Vink et al. ${ }^{(15)}$} & FTND & & Smokers & $0.70(\mathrm{M})$ \\
\hline & & & & $0.83(\mathrm{~F})$ \\
\hline & & & Former smokers & $0.91(\mathrm{M})$ \\
\hline & & & & $0.83(\mathrm{~F})$ \\
\hline \multirow[t]{8}{*}{ Weinberger et al. ${ }^{(34)}$} & FTND & & Smokers with schizophrenia & 0.65 \\
\hline & MNWS & & & 0.58 \\
\hline & T-QSU F1 & & & 0.65 \\
\hline & T-QSU F2 & & & 0.69 \\
\hline & FTND & & Smokers without psychiatric disorders & 0.82 \\
\hline & MNWS & & & 0.64 \\
\hline & T-QSU F1 & & & 0.79 \\
\hline & T-QSU F2 & & & 0.81 \\
\hline
\end{tabular}

M: males; F: females; FTND: Fagerström Test for Nicotine Dependence; HSI: Heaviness of Smoking Index; CPD: cigarettes (smoked) per day; USAF BMT: United States Air Force basic military training; FTQ: Fagerström Tolerance Questionnaire; MNWS: Minnesota Nicotine Withdrawal Scale; T-QSU: Tiffany Questionnaire for Smoking Urges; and F: factor. 
between applications. ${ }^{(27)}$ The FTND presented an excellent correlation coefficient, similar to those obtained in previous studies involving individuals without psychiatric disorders. The second study involved a sample of smokers hospitalized for depressive disorders. In that study, the FTND was applied at baseline and after a three-week interval. Although the authors reported that the results were satisfactory, the correlation coefficients were not presented. In that study, the application and reapplication of the instrument were carried out in different manners, a methodological limitation that might have interfered with the coefficient of reliability, affecting the result of the investigation. ${ }^{(24)} \mathrm{ln}$ the third study, two groups (individuals with and without schizophrenia) were investigated in a study on the reliability of the FTND. ${ }^{(34)}$ The authors found that the correlation coefficient was lower (0.65) in the group with schizophrenia, although, again, the interval between FTND applications was not reported. In the majority of those studies, the time elapsed since the last cigarette was not determined.

It should be borne in mind that, although the FTND can also be administered heterogeneously, no studies evaluating inter-rater reliability were identified.

\section{Internal consistency and factorial analysis}

We identified 14 studies that evaluated the internal consistency of the FTND. In those studies, the Cronbach's alpha coefficient ranged from 0.55 to 0.74 , indicating that the FTND has moderate internal consistency (Table 3).

The internal consistency of the FTND was evaluated and compared with that of the FTQ in four studies, all of which showed that of the FTND to be superior. ${ }^{(6,21,23,24)}$ However, studies in which the FTND was compared with other instruments for the evaluation of nicotine dependence, such as the Minnesota Nicotine Withdrawal Scale (MNWS) and the Tiffany Questionnaire for Smoking Urges (T-QSU), found the internal consistency of the FTND to be inferior. ${ }^{(22,32,34)}$

In two different studies, it was found that FTND questions 2 and 3 add no relevant information, suggesting that the removal of these questions would increase the internal consistency of the FTND..$^{(3,8)}$
In one study, the overall score on the FTND was found to present an alpha of 0.67 , the internal consistency being adequate $(\alpha=0.70)$ for factor 1 , whereas that of factor 2 (items 3 and 5) was extremely low $(\alpha=0.40)$, possibly due to the small number of items in the last factor. ${ }^{(7)}$

In the present meta-analysis, twelve studies involving factorial analysis of the FTND were identified. Initial studies of factorial analysis indicated that the FTND presented only one factor. ${ }^{(6)}$ Two studies, one involving light smokers ${ }^{(8)}$ and the other conducted in the general population, ${ }^{(31)}$ also showed the FTND to be unifactorial. However, most recent studies have reported that the FTND measures two factors, with small differences observed among the questions that compose the factors. ${ }^{(7,12,14,16,21,23,25-27,29)}$

Regarding the distribution of the items by factor, questions 3 and 5 are believed to belong to a single factor related to the urgency to restore nicotine levels (factor 2, designated the "Smoking Pattern" factor), whereas questions 2, 4 and 6 are thought to be part of another factor related to the pattern of consumption (factor 1 , designated the "Morning Pattern" factor). In various studies, question 1 ("How soon after you wake up do you smoke?") has been found to be present in both factors, ${ }^{(12,29)}$ to be part of factor $2,{ }^{(14,21,23,25)}$ or to remain in factor $1 .^{(7,16,27)}$ Given that factor 2 consists of only two items in some studies, its ability to represent a single factor has been questioned. ${ }^{(7)}$

\section{Validity and correlation of the FTND with other measures of nicotine dependence}

We identified only one study in which the sensitivity and specificity of the FTND was evaluated. ${ }^{(13)}$ That study, conducted in Japan, involved a sample of patients with cancer and used the Diagnostic and Statistical Manual of Mental Disorders (Revised Third Edition) as the gold standard. The FTND showed satisfactory sensitivity (0.75) and specificity (0.80) when a cut-off score of five was used. Therefore, the Japanese-language version proved to be valid and reliable for the evaluation of nicotine dependence in cancer patients.

Two studies that examined the validity and reliability of the HSI adopted the FTND as the gold standard. ${ }^{(9,11)}$ When a cut-off score of four was used, the HSI showed adequate sensitivity 
Table 3 - Internal consistency in studies evaluating the Fagerström Test for Nicotine Dependence.

\begin{tabular}{|c|c|c|c|}
\hline Study & Test & Subjects & Cronbach's $\alpha$ \\
\hline \multirow[t]{2}{*}{ Heatherton et al..$^{(6)}$} & FTND & Adult smokers & 0.61 \\
\hline & FTQ & & 0.48 \\
\hline \multirow[t]{2}{*}{ Payne et al. ${ }^{(23)}$} & FTND & Smokers & 0.56 \\
\hline & FTQ & & 0.49 \\
\hline \multirow[t]{4}{*}{ Pomerleau et al. ${ }^{(24)}$} & FTND & Smokers & 0.64 \\
\hline & FTQ & & $0.47(1)$ \\
\hline & FTND & Smokers with depression (2) & $0.61(2)$ \\
\hline & FTQ & & $0.58(3)$ \\
\hline Mikami et al. ${ }^{(13)}$ & FTND & Cancer patients & 0.66 \\
\hline \multirow[t]{4}{*}{ Etter et al. ${ }^{(8)}$} & FTND & Light smokers & $0.70^{*}$ \\
\hline & $\mathrm{HSI}$ & & $0.72^{* * *}$ \\
\hline & FTND & & $0.67^{*}$ \\
\hline & HSI & & $0.72^{* *}$ \\
\hline Haddock et al..$^{(7)}$ & FTND & Young smokers in USAF BMT & 0.67 \\
\hline Carmo et al..$^{(3)}$ & FTND & Smokers & 0.64 \\
\hline \multirow[t]{3}{*}{ Burling \& Burling ${ }^{(21)}$} & FTND & Drug-/alcohol-dependent smokers & 0.59 \\
\hline & FTQ & & 0.49 \\
\hline & $\mathrm{HSl}$ & & 0.49 \\
\hline \multirow[t]{2}{*}{ John et al. ${ }^{(16)}$} & FTND & Smokers & $0.55(1)$ \\
\hline & & & $0.60(2)$ \\
\hline \multirow[t]{4}{*}{ Etter $^{(22)}$} & FTND & Smokers & 0.68 \\
\hline & CDS-12 & & 0.91 \\
\hline & CDS-5 & & 0.77 \\
\hline & $\mathrm{HSI}$ & & 0.63 \\
\hline \multirow[t]{4}{*}{ Vink et al. ${ }^{(15)}$} & FTND & Smokers & $0.65(\mathrm{M})$ \\
\hline & & & $0.69(\mathrm{~F})$ \\
\hline & & Former smokers & 0.66 (M) \\
\hline & & & $0.71(\mathrm{~F})$ \\
\hline \multirow[t]{2}{*}{ Wellman et al. ${ }^{(31)}$} & FTND & Smokers & 0.61 \\
\hline & $\mathrm{HONC}$ & & 0.82 \\
\hline \multirow[t]{3}{*}{ Okuyemi et al. ${ }^{(32)}$} & FTND & Light smokers & 0.63 \\
\hline & CD & & 0.64 \\
\hline & NDSS & & 0.80 \\
\hline \multirow[t]{8}{*}{ Weinberger et al. ${ }^{(34)}$} & FTND & Smokers with schizophrenia & 0.74 \\
\hline & MNWS & & 0.88 \\
\hline & T-QSU F1 & & 0.79 \\
\hline & T-QSU F2 & & 0.88 \\
\hline & FTND & Smokers without psychiatric disorders & 0.72 \\
\hline & MNWS & & 0.90 \\
\hline & T-QSU F1 & & 0.86 \\
\hline & T-QSU F2 & & 0.89 \\
\hline
\end{tabular}

(1): sample number 1; (2): sample number 2; (3): sample number 3; (M): males; (F): females; FTND: Fagerström Test for Nicotine Dependence; FTQ: Fagerström Tolerance Questionnaire; HSI: Heaviness of Smoking Index; USAF BMT: United States Air Force basic military training; CDS-12: 12-item Cigarette Dependence Scale; CDS-5: short (5-item) version of the CDS-12; HONC: Hooked on Nicotine Checklist; NDSS: Nicotine Dependence Syndrome Scale; MNWS: Minnesota Nicotine Withdrawal Scale; and T-QSU: Tiffany Questionnaire for Smoking Urges. *Smokers at baseline. **Smokers at follow-up.

and specificity in both studies. Other authors have analyzed the psychometric properties of two additional reduced versions of the FTND ${ }^{(11)}$ : the heavy smoking item (question 4) and the high early smoking item (question 1). However, the results were unsatisfactory. Further studies, using appropriate diagnostic instruments as gold standards and investigating the possible cut-off 
points for various populations, are needed in order to fully validate the HSI. It is of note that there have been few validation studies involving this instrument, which is extensively used the world over.

One study evaluated the performance of the FTND and compared it with other measures of nicotine dependence. ${ }^{(8)}$ The overall score on the FTND was significantly correlated with nicotine concentration in saliva, with the number of times the subject tried to stop smoking within the preceding 12 months, with the intensity of withdrawal symptoms and with the self-perception of dependency reported by the subject, suggesting the validity of the scale and its applicability in the clinical context.

In another study, the overall score on the FTND was also significantly associated with the intention to quit smoking, the history of 24-h quit attempts in the last year, the cigarette type (regular or light) and the number of pack-years, suggesting that the instrument has adequate criterion-related and predictive validity. ${ }^{(7)}$

In four separate studies, ${ }^{(12,21,27,32)}$ the correlations between FTND score and biological markers were investigated (Table 4). In a study on smokers with alcohol and nicotine dependence, a satisfactory correlation coefficient (0.59) was reported for the relationship between FTND score and carbon monoxide level. ${ }^{(21)}$ In contrast, a recent study involving light smokers showed that the correlation between FTND score and carbon monoxide level was very weak (0.19), as was the correlation $(0.24)$ between FTND score and saliva cotinine. ${ }^{(32)}$ In an investigation of the general population, ${ }^{(12)}$ a better correlation between FTND score and saliva cotinine (0.45) was observed. The results presented in these four studies indicate that, in general, the correlation between the FTND and the biological markers evaluated ranges from weak to moderate.

\section{Discussion}

The results of the investigations presented and analyzed in the current meta-analysis suggest that the FTND is reliable for the evaluation of smokers in different populations, although studies presenting better systematization of the intervals between evaluations and reporting the time elapsed since the last cigarette are still needed. For instance, for the study of test-retest reliability, the establishment of an appropriate interval between the first and second evaluation is considered to be of fundamental importance, since a short interval might increase the influence of memory and a long interval might result in greater variations (individual changes) regarding what is being measured (the pattern of tobacco consumption). In addition, although the FTND asks smokers to provide reasonably objective information regarding long-term smoking patterns, the fact that these smokers are in withdrawal can influence their responses to the items. ${ }^{(7)}$

The internal consistency of the FTND was better than that of the FTQ. However, compared with other instruments for the evaluation of

Table 4 - Studies of the correlation between the Fagerström Test for Nicotine Dependence and biological markers.

\begin{tabular}{llccc}
\hline \multicolumn{1}{c}{ Study } & \multicolumn{1}{c}{ Subjects } & Test & Biochemical marker & Correlation \\
\hline Burling \& Burling ${ }^{(21)}$ & Drug/alcohol dependent & FTND & Carbon monoxide & 0.59 \\
& & FTQ & & 0.49 \\
Buckley et al. ${ }^{(27)}$ & Smokers with chronic post-traumatic & FTND & Carbon monoxide & 0.49 \\
& Stress disorder & & Nicotine (mg/day) & 0.40 \\
Huang et al. ${ }^{(12)}$ & Smokers & FTND & Saliva cotinine & 0.38 \\
Okuyemi et al. ${ }^{(32)}$ & Light smokers & FTND & Saliva cotinine & 0.24 \\
& & & Carbon monoxide & 0.19 \\
& & CDS-5 & Saliva cotinine & 0.28 \\
& & & Carbon monoxide & 0.25 \\
& & NDSS & Saliva cotinine & 0.13 \\
\end{tabular}

FTND: Fagerström Test for Nicotine Dependence; FTQ: Fagerström Tolerance Questionnaire; HSI: Heaviness of Smoking Index; CDS-5: short (5-item) version of the Cigarette Dependence Scale; and NDSS: Nicotine Dependence Syndrome Scale. 
nicotine dependence, such as the MNWS and the T-QSU, the FTND yielded inferior results. This might be due to the number of factors evaluated by the FTND, which most authors have found to consist of two factors: one referring to the urgency to restore nicotine levels; and the other referring to the pattern of tobacco consumption. The correlations between the FTND and biological markers were found to be weak to moderate.

Despite the widespread use of the FTND in research and clinical practice, validity studies that might permit the definition of better FTND cut-off points for different populations are still needed. On the basis of the present metaanalysis, we conclude that further studies of the FTND are needed in order to assess inter-rater reliability and especially to define its sensitivity, specificity, positive predictive value and negative predictive value. To that end, structured interviews such as the Structured Clinical Interview for the Diagnostic and Statistical Manual of Mental Disorders, Fourth Edition or the Composite International Diagnostic Interview, should be used for comparison. The results of such studies could indicate whether the psychometric qualities of the FTND make it suitable for extensive use.

\section{References}

1. Das SK. Harmful health effects of cigarette smoking. Mol Cell Biochem. 2003;253(1-2):159-65.

2. Anderson P. Global use of alcohol, drugs and tobacco. Drug Alcohol Rev. 2006;25(6):489-502.

3. Carmo JT, Pueyo AA. A adaptaçäo ao português do Fagerström test for nicotine dependence (FTND) para avaliar a dependência e tolerância à nicotina em fumantes brasileiros. Rev. Bras. Med. 2002;59(1/2):73-80.

4. Fagerström KO. Measuring degree of physical dependence to tobacco smoking with reference to individualization of treatment. Addict Behav. 1978;3(3-4):235-41.

5. Fagerstrom KO, Schneider NG. Measuring nicotine dependence: a review of the Fagerstrom Tolerance Questionnaire. J Behav Med. 1989;12(2):159-82.

6. Heatherton TF, Kozlowski LT, Frecker RC, Fagerström KO. The Fagerström Test for Nicotine Dependence: a revision of the Fagerström Tolerance Questionnaire. Br J Addict. 1991;86(9):1119-27.

7. Haddock CK, Lando H, Klesges RC, Talcott GW, Renaud EA. A study of the psychometric and predictive properties of the Fagerström Test for Nicotine Dependence in a population of young smokers. Nicotine Tob Res. 1999;1(1):59-66.

8. Etter JF, Duc TV, Perneger TV. Validity of the Fagerström test for nicotine dependence and of the Heaviness of Smoking Index among relatively light smokers. Addiction. 1999;94(2):269-81.
9. Chabrol H, Niezborala M, Chastan E, de Leon J. Comparison of the Heavy Smoking Index and of the Fagerstrom Test for Nicotine Dependence in a sample of 749 cigarette smokers. Addict Behav. 2005;30(7):1474-7.

10. Becoña E, Vázquez FL. The Fagerström Test for Nicotine Dependence in a Spanish sample. Psychol Rep. 1998;83(3 Pt 2):1455-8.

11. de Leon J, Diaz FJ, Becoña E, Gurpegui M, Jurado D, Gonzalez-Pinto A. Exploring brief measures of nicotine dependence for epidemiological surveys. Addict Behav. 2003;28(8):1481-6.

12. Huang $\mathrm{Cl}$, Lin $\mathrm{HH}$, Wang $\mathrm{HH}$. The psychometric properties of the Chinese version of the Fagerstrom Test for Nicotine Dependence. Addict Behav. 2006;31(12):2324-7.

13. Mikami 1, Akechi T, Kugaya A, Okuyama T, Nakano T, Okamura $\mathrm{H}$, et al. Screening for nicotine dependence among smoking-related cancer patients. Jpn J Cancer Res. 1999;90(10):1071-5.

14. Breteler MH, Hilberink SR, Zeeman G, Lammers SM. Compulsive smoking: the development of a Rasch homogeneous scale of nicotine dependence. Addict Behav. 2004;29(1):199-205.

15. Vink JM, Willemsen G, Beem AL, Boomsma Dl. The Fagerström Test for Nicotine Dependence in a Dutch sample of daily smokers and ex-smokers. Addict Behav. 2005;30(3):575-9.

16. John U, Meyer C, Schumann A, Hapke U, Rumpf HJ, Adam C, et al. A short form of the Fagerström Test for Nicotine Dependence and the Heaviness of Smoking Index in two adult population samples. Addict Behav. 2004;29(6):1207-12.

17. Uysal MA, Kadakal F, Karşidağ C, Bayram NG, Uysal 0, Yilmaz V. Fagerstrom test for nicotine dependence: reliability in a Turkish sample and factor analysis. Tuberk Toraks. 2004;52(2):115-21.

18. Ebbert JO, Patten CA, Schroeder DR. The Fagerström Test for Nicotine Dependence-Smokeless Tobacco (FTND-ST). Addict Behav. 2006;31(9):1716-21.

19. Heatherton TF, Kozlowski LT, Frecker RC, Rickert W, Robinson J. Measuring the heaviness of smoking: using self-reported time to the first cigarette of the day and number of cigarettes smoked per day. $\mathrm{Br} \mathrm{J}$ Addict. 1989;84(7):791-9.

20. Kozlowski LT, Porter CQ, Orleans CT, Pope MA, Heatherton T. Predicting smoking cessation with selfreported measures of nicotine dependence: FTQ, FTND, and HSl. Drug Alcohol Depend. 1994;34(3):211-6.

21. Burling AS, Burling TA. A comparison of self-report measures of nicotine dependence among male drug/ alcohol-dependent cigarette smokers. Nicotine Tob Res. 2003;5(5):625-33.

22. Etter JF. A comparison of the content-, construct- and predictive validity of the cigarette dependence scale and the Fagerström test for nicotine dependence. Drug Alcohol Depend. 2005;77(3):259-68.

23. Payne TJ, Smith PO, McCracken LM, McSherry WC, Antony MM. Assessing nicotine dependence: a comparison of the Fagerström Tolerance Questionnaire (FTQ) with the Fagerström Test for Nicotine Dependence (FTND) in a clinical sample. Addict Behav. 1994;19(3):307-17.

24. Pomerleau CS, Carton SM, Lutzke ML, Flessland KA, Pomerleau OF. Reliability of the Fagerstrom Tolerance Questionnaire and the Fagerstrom Test for Nicotine Dependence. Addict Behav. 1994;19(1):33-9. 
25. Radzius A, Gallo JJ, Epstein DH, Gorelick DA, Cadet JL, Uhl GE, Moolchan ET. A factor analysis of the Fagerström Test for Nicotine Dependence (FTND). Nicotine Tob Res. 2003;5(2):255-40.

26. Hughes JR, Oliveto AH, Riggs R, Kenny M, Liguori A, Pillitteri JL, et al. Concordance of different measures of nicotine dependence: two pilot studies. Addict Behav. 2004;29(8):1527-39.

27. Buckley TC, Mozley SL, Holohan DR, Walsh K, Beckham JC, Kassel JD. A psychometric evaluation of the Fagerström Test for Nicotine Dependence in PTSD smokers. Addict Behav. 2005;30(5):1029-33.

28. Hudmon KS, Pomerleau CS, Brigham J, Javitz H, Swan GE. Validity of retrospective assessments of nicotine dependence: a preliminary report. Addict Behav. 2005;30(3):613-7.

29. Richardson CG, Ratner PA. A confirmatory factor analysis of the Fagerstrom Test for Nicotine Dependence. Addict Behav. 2005;30(4):697-709.

30. Steinberg ML, Williams JM, Steinberg HR, Krejci JA, Ziedonis DM. Applicability of the Fagerström Test for
Nicotine Dependence in smokers with schizophrenia. Addict Behav. 2005;30(1):49-59.

31. Wellman RJ, DiFranza JR, Pbert L, Fletcher KE, Flint A, Young $\mathrm{MH}$, et al. A comparison of the psychometric properties of the hooked on nicotine checklist and the modified Fagerström tolerance questionnaire. Addict Behav. 2006;31(3):486-95.

32. Okuyemi KS, Pulvers KM, Cox LS, Thomas JL, Kaur H, Mayo MS, et al. Nicotine dependence among African American light smokers: a comparison of three scales. Addict Behav. 2007;32(10):1989-2002.

33. Sledjeski EM, Dierker LC, Costello D, Shiffman S, Donny E, Flay BR, et al. Predictive validity of four nicotine dependence measures in a college sample. Drug Alcohol Depend. 2007;87(1):10-9.

34. Weinberger AH, Reutenauer EL, Allen TM, Termine A, Vessicchio JC, Sacco KA, et al. Reliability of the Fagerström Test for Nicotine Dependence, Minnesota Nicotine Withdrawal Scale, and Tiffany Questionnaire for Smoking Urges in smokers with and without schizophrenia. Drug Alcohol Depend. 2007;86(2-3):278-82.

\section{About the authors}

Izilda Carolina de Meneses-Gaya

Psychologist in the Department of Neurosciences and Behavior. University of São Paulo at Ribeirão Preto School of Medicine, Ribeirão Preto, Brazil.

\section{Antonio Waldo Zuardi}

Head of the Department of Neurosciences and Behavior. University of São Paulo at Ribeirão Preto School of Medicine, Ribeirão Preto, Brazil.

\section{Sonia Regina Loureiro}

Associate Professor in the Department of Neurosciences and Behavior. University of São Paulo at Ribeirão Preto School of Medicine, Ribeirão Preto, Brazil.

\section{José Alexandre de Souza Crippa}

Professor of Psychiatry at the University of São Paulo at Ribeirão Preto School of Medicine, Ribeirão Preto, Brazil. 
Appendix 1 - Items and scoring for the Fagerström Test for Nicotine Dependence.

$\frac{\text { Question }}{1 . \text { How soon after you wake up do you smoke your first cigarette? }}$

2. Do you find it difficult to refrain from smoking in places where it is forbidden, e.g., in church, at the library, in the cinema, etc.?

3. Which cigarette would you most hate to give up?

4. How many cigarettes/day do you smoke?

5. Do you smoke more frequently during the first hours after waking than during the rest of the day?

6. Do you smoke if you are so ill that you are in bed most of the day?
Answers

Within 5 minutes

6-30 minutes

31-60 minutes

After 60 minutes

Yes

No

The first one in the morning

Any other

10 or less

11-20

21-30

31 or more

Yes

No 0

Yes 1

No 0

OPermission to use this scale for purposes other than research must be obtained from K.O. Fagerström. 